\title{
Kinetics of the [4+2] cycloaddition of cyclopentadiene with $(E)$-2-aryl-1-cyano-1-nitroethenes
}

\author{
Radomir Jasiński • Magdalena Kwiatkowska • \\ Andrzej Barański
}

Received: 18 August 2011/ Accepted: 9 February 2012/Published online: 2 March 2012

(c) The Author(s) 2012. This article is published with open access at Springerlink.com

\begin{abstract}
The electrophilicity of (E)-2-aryl-1-cyano-1nitroethenes is not sufficient to induce a zwitterionic course of their [4+2] cycloaddition to cyclopentadiene. The onestep mechanism of these reactions is indicated by the activation parameters, and the substituent and solvent effects on the reaction.
\end{abstract}

Keywords [4+2] Cycloaddition · Nitroalkene ·

Kinetics · Mechanism

\section{Introduction}

For the last decade, reactions of conjugated nitroalkenes have aroused our considerable interest [1-9], and we have exerted considerable effort to examine their reactivity in thermally allowed cycloaddition reactions. Especially the $[4+2]$ cycloaddition reactions of cyclopentadiene (1) with strong electrophilic (E)-2-aryl-1-cyano-1-nitroethenes $\mathbf{2 a - 2 g}$ were investigated $[4-6,9]$.

By means of HPLC and NOESY experiments [6], it has been unequivocally established that this reaction leads to the corresponding 6-endo-aryl-5-endo-cyano-5-exo-nitronorbornenes 3a-3g and 6-exo-aryl-5-exo-cyano-5-endonitronorbornenes $\mathbf{4 a}-\mathbf{4 g}$ as the only reaction products. The stereospecific reaction course suggests that, independently of the nitroalkene electrophilicity, this reaction occurs according to a concerted mechanism (paths A and B).

R. Jasiński $(\bowtie) \cdot$ M. Kwiatkowska · A. Barański Institute of Organic Chemistry and Technology, Cracow University of Technology, Warszawska 24, 31-155 Cracow, Poland

e-mail: radomir@chemia.pk.edu.pl
However, stereospecificity cannot be regarded as sufficient evidence of the concertedness [10-12]. Nevertheless, it cannot be ruled out that the reaction proceeds by a zwitterionic mechanism [10, 13-15] (paths C and D), while preserving the original nitroalkene configuration in cycloadducts, when the activation barrier for the carbocyclic ring closure in postulated intermediates is lower than the corresponding barrier for rotation around the $\mathrm{C}-\mathrm{C}$ bond of the cyanonitroethyl moiety. The aim of this work was to evaluate the nature of the transition complexes and to confirm or exclude the presence of zwitterionic intermediates on the reaction paths. For this purpose, the kinetics of the title reaction were investigated, and the substituent and solvent effects as well as activation parameters were determined.

\section{Results and discussion}

Kinetic studies (Table 1) showed that the rate constants of the reactions leading to the nitronorbornenes $\mathbf{3 a}-\mathbf{3 g}$ and 4a-4g (Scheme 1) increase with the nitroalkene electrophilicity. In particular, the rate constants $k_{\mathrm{A}}$ and $k_{\mathrm{B}}$ for the reactions involving the least electrophilic $(E)-2-(p-$ methoxyphenyl)-1-cyano-1-nitroethene (2a) $(\omega=3.14 \mathrm{eV}$ [5]) are $0.08 \times 10^{-3} \mathrm{dm}^{3} \mathrm{~mol}^{-1} \mathrm{~s}^{-1}$ and $1.66 \times 10^{-3}$ $\mathrm{dm}^{3} \mathrm{~mol}^{-1} \mathrm{~s}^{-1}$, while those for the reactions with the most electrophilic (E)-2-(p-methoxycarbonylphenyl)-1-cyano-1nitroethene $(\mathbf{2 g}) \quad(\omega=3.80 \mathrm{eV} \quad$ [5] $)$ are $13.35 \times$ $10^{-3} \mathrm{dm}^{3} \mathrm{~mol}^{-1} \mathrm{~s}^{-1}$ and $83.42 \times 10^{-3} \mathrm{dm}^{3} \mathrm{~mol}^{-1} \mathrm{~s}^{-1}$, respectively. We investigated the substituent effect on the reaction using classical correlation analysis, seeking the best match between substrate reactivity $\left(\log k_{\mathrm{A}}\right.$ and $\log k_{\mathrm{B}}$ ) and the values of the Hammett constants $\sigma^{+}, \sigma_{\mathrm{p}}, \sigma_{\mathrm{R}}, \sigma_{\mathrm{I}}[16]$ of the substituents. The best linear correlations $(R=0.995$ for the reaction $\mathbf{1}+\mathbf{2} \rightarrow \mathbf{3}$ and 0.991 for the reaction 
Table 1 Results of kinetic measurements of [4+2] cycloaddition of cyclopentadiene with (E)-2-aryl-1-cyano-1-nitroethenes $\mathbf{2 a - 2 g}$

\begin{tabular}{|c|c|c|c|c|c|c|c|c|c|c|c|}
\hline \multicolumn{4}{|c|}{ Nitroalkene } & \multirow[t]{2}{*}{ Solvent $\left[E_{\mathrm{T}}(30)\right]$} & \multirow[t]{2}{*}{$T /{ }^{\circ} \mathrm{C}$} & \multirow{2}{*}{$\begin{array}{l}k_{\text {total }} \times 10^{3} / \\
\mathrm{dm}^{3} \mathrm{~mol}^{-1} \mathrm{~s}^{-1}\end{array}$} & \multirow{2}{*}{$\begin{array}{l}\text { Isomer ratio } \\
\gamma[\mathbf{3}] /[\mathbf{4}]\end{array}$} & \multirow{2}{*}{$\begin{array}{l}k_{\mathrm{A}} \times 10^{3} / \\
\mathrm{dm}^{3} \mathrm{~mol}^{-1} \mathrm{~s}^{-1}\end{array}$} & \multirow{2}{*}{$\begin{array}{l}k_{\mathrm{B}} \times 10^{3} / \\
\mathrm{dm}^{3} \mathrm{~mol}^{-1} \mathrm{~s}^{-1}\end{array}$} & \multirow[t]{2}{*}{$R$} & \multirow[t]{2}{*}{ SD } \\
\hline $\mathrm{Nr}$ & $\mathrm{R}$ & $\sigma_{\mathrm{p}}$ & $\omega / \mathrm{eV}$ & & & & & & & & \\
\hline $2 \mathbf{a}$ & $\mathrm{OCH}_{3}$ & -0.27 & 3.14 & Nitromethane (46.3) & 25 & 1.74 & 0.05 & 0.08 & 1.66 & 0.998 & 0.01 \\
\hline $2 \mathbf{b}$ & $\mathrm{CH}_{3}$ & -0.17 & 3.31 & Nitromethane (46.3) & 25 & 3.28 & 0.09 & 0.27 & 3.01 & 0.998 & 0.02 \\
\hline $2 \mathrm{c}$ & $\mathrm{H}$ & 0.00 & 3.42 & Nitromethane (46.3) & 25 & 6.23 & 0.12 & 0.67 & 5.56 & 0.998 & 0.02 \\
\hline 2d & $\mathrm{F}$ & 0.06 & 3.50 & Nitromethane (46.3) & 25 & 7.26 & 0.12 & 0.78 & 6.48 & 0.997 & 0.03 \\
\hline $2 e$ & $\mathrm{Cl}$ & 0.23 & 3.68 & Nitromethane (46.3) & 25 & 22.46 & 0.14 & 2.76 & 19.70 & 0.998 & 0.03 \\
\hline $2 f$ & $\mathrm{Br}$ & 0.23 & 3.71 & Nitromethane (46.3) & 25 & 25.13 & 0.14 & 3.09 & 22.04 & 0.998 & 0.04 \\
\hline $2 \mathrm{~g}$ & $\mathrm{COOCH}_{3}$ & 0.45 & 3.80 & Nitromethane (46.3) & 5 & 35.15 & 0.15 & 4.58 & 30.57 & 0.998 & 0.05 \\
\hline $2 \mathrm{~g}$ & $\mathrm{COOCH}_{3}$ & 0.45 & 3.80 & Nitromethane (46.3) & 15 & 59.99 & 0.15 & 7.82 & 52.17 & 0.998 & 0.05 \\
\hline $2 \mathrm{~g}$ & $\mathrm{COOCH}_{3}$ & 0.45 & 3.80 & Nitromethane (46.3) & 25 & 96.77 & 0.16 & 13.35 & 83.42 & 0.997 & 0.07 \\
\hline $2 \mathrm{~g}$ & $\mathrm{COOCH}_{3}$ & 0.45 & 3.80 & Dichloroethane (41.9) & 25 & 34.46 & 0.12 & 3.69 & 30.77 & 0.999 & 0.04 \\
\hline $2 \mathrm{~g}$ & $\mathrm{COOCH}_{3}$ & 0.45 & 3.80 & Dichloromethane (41.1) & 25 & 33.23 & 0.12 & 3.56 & 29.67 & 0.999 & 0.05 \\
\hline $2 \mathrm{~g}$ & $\mathrm{COOCH}_{3}$ & 0.45 & 3.80 & Chloroform (39.1) & 5 & 6.26 & 0.10 & 0.57 & 5.69 & 0.999 & 0.03 \\
\hline $2 \mathrm{~g}$ & $\mathrm{COOCH}_{3}$ & 0.45 & 3.80 & Chloroform (39.1) & 15 & 10.05 & 0.11 & 1.00 & 9.05 & 0.997 & 0.05 \\
\hline $2 \mathrm{~g}$ & $\mathrm{COOCH}_{3}$ & 0.45 & 3.80 & Chloroform (39.1) & 25 & 20.28 & 0.12 & 2.17 & 18.11 & 0.999 & 0.04 \\
\hline $2 \mathrm{~g}$ & $\mathrm{COOCH}_{3}$ & 0.45 & 3.80 & Tetrachloromethane (32.5) & 25 & 7.45 & 0.11 & 0.74 & 6.71 & 0.997 & 0.07 \\
\hline
\end{tabular}

Scheme 1

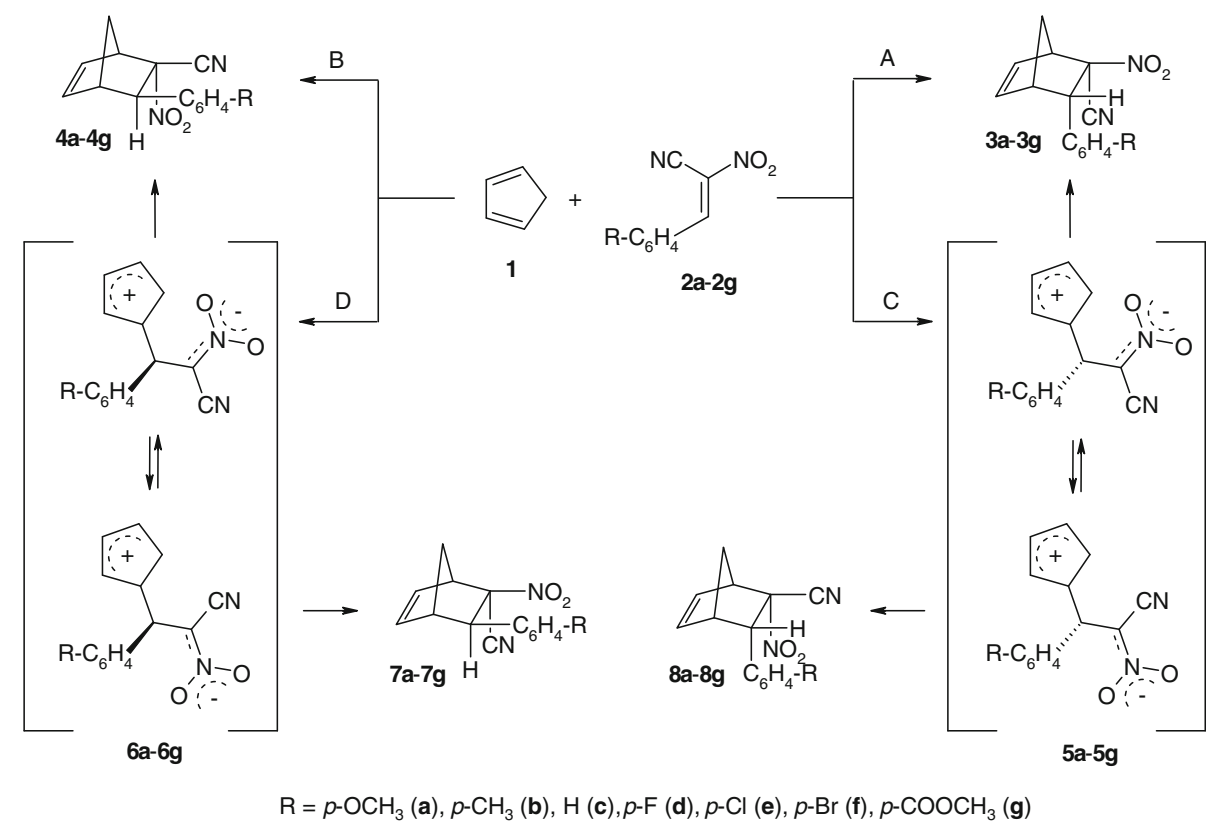

$\mathbf{1}+\mathbf{2} \rightarrow \mathbf{4})$ were obtained with the Hammett constants $\sigma_{\mathrm{p}}$ (Fig. 1). This means that the substituent effect is transferred to the reaction centers via both induction and resonance [17], and the transition complexes are similar regardless of the nitroalkene electrophilicity. These relationships are expressed by the Hammett Eqs. 1 and 2.

$\log k_{\mathrm{A}}=2.93 \cdot \sigma_{\mathrm{p}}-3.20 \quad(R=0.995)$

$\log k_{\mathrm{B}}=2.31 \cdot \sigma_{\mathrm{p}}-2.20 \quad(R=0.991)$

It is noteworthy that the values of the reaction constants $\rho$ in Eqs. 1 and 2 (2.93 for the reaction $\mathbf{1}+\mathbf{2} \rightarrow \mathbf{3}$ and 2.31 for the reaction $\mathbf{1}+\mathbf{2} \rightarrow \mathbf{4}$ ) are almost two times higher than those for concerted $[2+4]$ cycloadditions of cyclopentadiene with (E)-2-aryl-1-nitroethenes [2], while still being within the range typical of one-step cycloadditions [16]. Furthermore, the positive sign of the $\rho$ constant shows that charge transfer within the transition complexes of both competing reactions occurs from the cyclopentadiene substructure towards the nitroalkene substructure. Moreover, the relationships between $\log k_{\mathrm{A}}$ and $\log k_{\mathrm{B}}$ and the nitroalkene global electrophilicity indexes $\omega$ are similar. In this case, however, the correlations are slightly lower. 

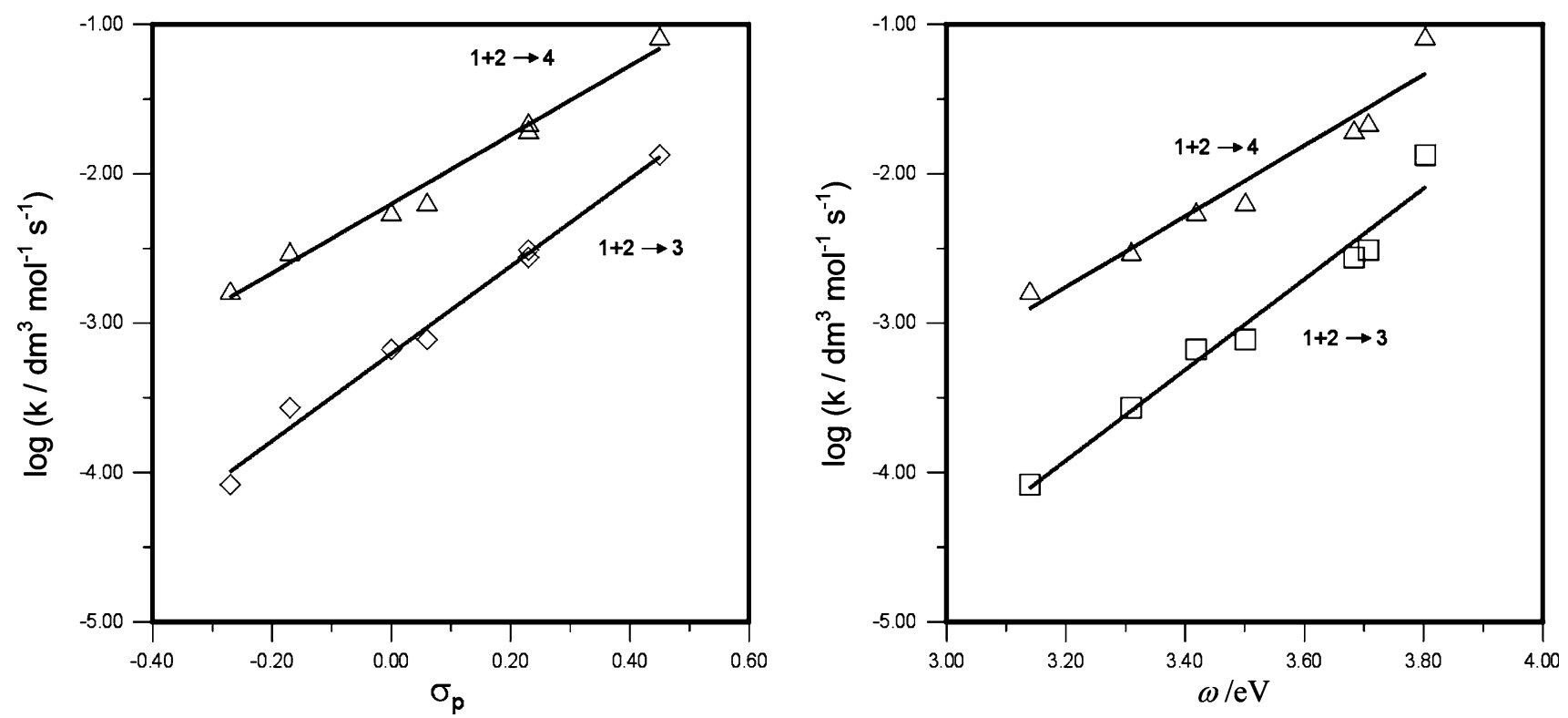

Fig. 1 Plot of $\log k$ versus Hammett constants $\sigma_{\mathrm{p}}$ and global electrophilicity index $\omega$ for the [4+2] cycloaddition of cyclopentadiene with (E)-2aryl-1-cyano-1-nitroethenes $\mathbf{2 a - 2}$ (at $25^{\circ} \mathrm{C}$ in nitromethane)

$$
\begin{array}{ll}
\log k_{\mathrm{A}}=3.04 \cdot \omega-13.64 & (R=0.986) \\
\log k_{\mathrm{B}}=2.37 \cdot \omega-10.34 & (R=0.971)
\end{array}
$$

In order to gain more insight into the nature of the transition complexes, we studied the effect of solvent polarity on the reaction kinetics. This was done for the reaction of the most electrophilic nitroalkene $\mathbf{2 g}$ (Table 1). The cycloadditions $1+\mathbf{2 g} \rightarrow \mathbf{3 g}$ and $\mathbf{1}+\mathbf{2 g} \rightarrow \mathbf{4 g}$ were found to occur more rapidly in polar than in non-polar solvents. This suggests that the transition complexes of the reactions tested are more polar than the substrates. This is consistent with the magnitude of dipole moments $(\mu=7.36 / 8.54 \mathrm{D})$ of the respective critical structures located on the reaction potential energy hypersurface using B3LYP/6-31 g(d) calculations [5].

To obtain a quantitative description of the solvent effect on the reaction rate, we studied correlations between substrate reactivity and the solvent polarity constants such as dielectric constant $\varepsilon$, dipole moment $\mu$, Berson constant $\Omega$, and Reichardt-Dimroth $E_{\mathrm{T}}(30)$ constant $[18,19]$. The best linear correlations were obtained for the $E_{\mathrm{T}}(30)$ constants (Eqs. 5, 6) (Fig. 2).

$$
\begin{array}{ll}
\log k_{\mathrm{A}}=0.09 \cdot E_{\mathrm{T}}-6.08 & (R=0.987) \\
\log k_{\mathrm{B}}=0.08 \cdot E_{\mathrm{T}}-4.76 & (R=0.994)
\end{array}
$$

These data prove that solvent polarity affects the rate of $1+2 \mathrm{~g}$ cycloaddition to a much higher extent than that for the reaction involving (E)-2-phenyl-1-nitroethene [2]. However, the sensitivity constants in Eqs. 5 and 6 do not exceed 0.1 and are below the typical range observed for ionic reactions $[18,20]$.

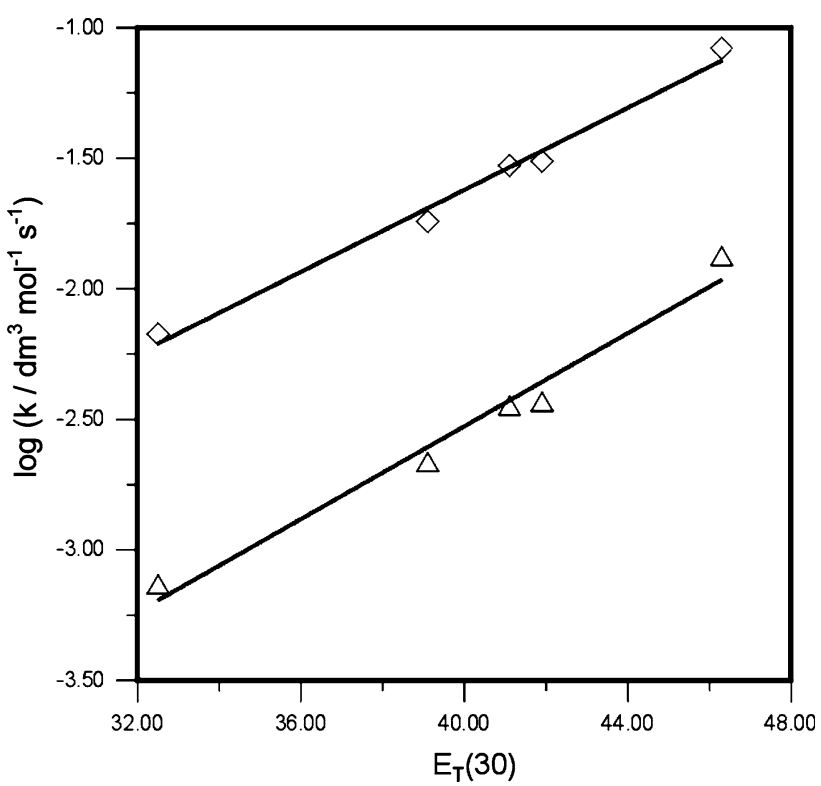

Fig. 2 Plot of $\log k$ versus Reichardt-Dimroth $E_{\mathrm{T}}(30)$ constants for the [4+2] cycloaddition of cyclopentadiene with $(E)-2-(p$-methoxycarbonylphenyl)-1-cyano-1-nitroethene $(\mathbf{2 g})\left(\right.$ at $\left.25{ }^{\circ} \mathrm{C}\right)$

Hence, the nature of the Hammett and Reichardt-Dimroth relationships suggests that the reactions $1+\mathbf{2} \rightarrow \mathbf{3}$ and $\mathbf{1}+\mathbf{2} \rightarrow \mathbf{4}$ do not proceed according to a zwitterionic mechanism [21] (paths $\mathrm{C}$ and D). The values of activation parameters (Table 2) lead to similar conclusions. These parameters were determined from the rate constants of the reactions $\mathbf{1}+\mathbf{2 g} \rightarrow \mathbf{3 g}$ and $\mathbf{1}+\mathbf{2 g} \rightarrow \mathbf{4 g}$ at 5,15 , and $25^{\circ} \mathrm{C}$ using the Eyring equation in the form: 
Table 2 Activation parameters for [4+2] cycloaddition of cyclopentadiene with (E)-2-(p-methoxycarbonylphenyl)-1-cyano-1-nitroethene (2g)

\begin{tabular}{|c|c|c|c|c|}
\hline & \multicolumn{2}{|l|}{ Nitromethane } & \multicolumn{2}{|l|}{ Chloroform } \\
\hline & $1+2 g \rightarrow 3 g$ & $1+2 g \rightarrow 4 g$ & $1+2 g \rightarrow 3 g$ & $1+2 g \rightarrow 4 g$ \\
\hline$\Delta H^{\neq} / \mathrm{kJ} \mathrm{mol}^{-1}$ & 34.3 & 32.2 & 43.5 & 37.3 \\
\hline$\Delta S^{\neq} / \mathrm{J} \mathrm{mol}^{-1} \mathrm{~K}^{-1}$ & -165.4 & -157.4 & -149.9 & -153.2 \\
\hline
\end{tabular}

$\log (k / T)=10.319+\Delta S^{\neq} / 4.576-\Delta H^{\neq} / 4.576 T$

In particular, the activation enthalpies $\left(\Delta H^{\neq}\right)$were estimated from the slopes of the plots of logarithm of the ratio of $k_{\mathrm{A}}$ or $k_{\mathrm{B}}$ by the absolute temperature $(T)$ versus reciprocal of the absolute temperature $(1 / T)$, while the entropies of activation $\left(\Delta S^{\neq}\right)$were determined from the intercepts of these plots. It follows from the data in Table 2 that the $\Delta H^{\neq}$values for the cycloadditions $\mathbf{1}+\mathbf{2 g} \rightarrow \mathbf{3 g}$ and $\mathbf{1}+\mathbf{2 g} \rightarrow \mathbf{4 g}$ do not exceed $46 \mathrm{~kJ} \mathrm{~mol}^{-1}$. They are typical for the reactions, where the energy changes within the transition complexes resulting from breaking of $\pi$ bonds existing in the substrates and formation of new $\sigma$ bonds present in the cycloadducts compensate one another [16]. On the other hand, the $\Delta S^{f}$ values are high and negative $(-150$ to $-165 \mathrm{~J}$ $\mathrm{mol}^{-1} \mathrm{~K}^{-1}$ ), both in the moderately polar chloroform and the highly polar nitromethane. This is typical for one-step cycloadditions proceeding through highly rigid transition complexes [22-24]. By comparison, $\Delta S^{\neq}$for a two-step cycloaddition of 1,1-dimethoxy-1,3-butadiene with tetracyanoethene is $-26 \mathrm{~J} \mathrm{~mol}^{-1} \mathrm{~K}^{-1}$ [25]. It is noticeable that the entropy changes in the transition state are much higher in our case than those for a similar reaction involving $(E)$-2-phenyl-1-nitroethene $\left(\Delta S^{\neq}=-102.5\right.$ to $\left.-120 \mathrm{~J} \mathrm{~mol}^{-1} \mathrm{~K}^{-1}[2]\right)$. This is probably due to the polarization and dispersion of the substrate interactions within the transition complexes, which should be much stronger in the case of more electrophilic (E)-2-aryl-1cyano-1-nitroethene than in the case of less electrophilic (E)-2-aryl-1-nitroethenes [26, 27]. This is indirectly confirmed by the depths of the pre-reaction local minima located on the potential energy hypersurface found for the reactions involving $(E)$-2-aryl-1-cyano-1-nitroethenes $[5,9]$ and $(E)$-2-aryl-1-nitroethenes [1].

\section{Conclusion}

In summary, the electrophilicity of (E)-2-aryl-1-cyano-1nitroethenes is not sufficient to induce an ionic course of their [4+2] cycloaddition to cyclopentadiene. The activation parameters and the substituent and solvent effects on the reaction studied indicate its non-ionic mechanism.

\section{Experimental}

All solvents employed for kinetic measurements were purified by standard methods [28]. Cyclopentadiene (1) was prepared by pyrolysis of commercially available dicyclopentadiene (Aldrich) at $180-200{ }^{\circ} \mathrm{C}$, according to a known method [29]. Before use it was distilled under atmospheric pressure, using a $25-\mathrm{cm}$ Vigreux column. (E)-2-Aryl-1-cyano-1-nitroethenes $\mathbf{2 a - 2 g}$ were obtained by condensation of appropriate aromatic aldehydes with nitroacetonitrile, according to a reported procedure [30]. Their purity was confirmed by HPLC analyses.

Kinetic experiments were carried out in a glass reactor supplied with a thermostatically controlled jacket, magnetic stirrer, thermometer, reflux condenser, and sampling device. Liquid chromatography (HPLC) was done using a Knauer apparatus, equipped with a UV-Vis detector $(\lambda=254 \mathrm{~nm})$. For monitoring of the reaction progress a LiChrospher 100RP column $(4 \times 240 \mathrm{~mm})$ thermostated at $5{ }^{\circ} \mathrm{C}$ was used, and $70 \%$ methanol at a flow rate of $1.1 \mathrm{~cm}^{3} \mathrm{~min}^{-1}$ was applied as the eluent.

\section{Kinetic procedure}

The overall rate constants $\left(k_{\text {total }}\right)$ were determined by monitoring the decrease of the HPLC peak area $(A)$ corresponding to cyclopentadiene. It was found that the product composition was controlled kinetically, since the ratio of the products $(\gamma=[3] /[4])$ was constant throughout the reaction course. The kinetic experiments were carried out at 5,15 , and $25{ }^{\circ} \mathrm{C}$ up to $70-80 \%$ completion, using in each case equimolar quantities of substrates. In definite time intervals $250-\mathrm{mm}^{3}$ samples were taken out of the reactor with a microsyringe and analyzed immediately by HPLC. In this way 15 series of measurements were completed. The regression analysis was carried out using MATCAD 07. It showed excellent linear relationships $(R>0.99)$ between $1 / A$ and time $t$ for all kinetic runs, using the second-order kinetic Eq. 8 of the form:

$1 / A=-k_{\text {total }} \cdot t+$ const

The $k_{\text {total }}$ and $\gamma$ values were then applied for calculation of the rate constants $k_{\mathrm{A}}$ and $k_{\mathrm{B}}$ according to Eqs. 9 and 10: $k_{\mathrm{A}}=\gamma \cdot k_{\text {total }} /(\gamma+1)$ 
$k_{\mathrm{B}}=k_{\mathrm{total}} /(\gamma+1)$

The second-order rate constants for different temperatures and solvents obtained by this method are summarized in Table 1.

Acknowledgments We wish to express our thanks to Prof. V. M. Berestovitskaya from Herzen Russian State Pedagogical University in St. Petersburg for valuable discussions during the synthesis of $(E)-2-$ aryl-1-cyano-1-nitroethenes. This work was supported by the Polish Ministry of Science and Higher Education (Grant C-2/508/BW/2010).

Open Access This article is distributed under the terms of the Creative Commons Attribution License which permits any use, distribution, and reproduction in any medium, provided the original author(s) and the source are credited.

\section{References}

1. Jasiński R, Koifman O, Barański A (2011) Central Eur J Chem 9:1008

2. Jasiński R, Kwiatkowska A, Barański A (2011) J Phys Org Chem 24:843

3. Jasiński R, Mikulska M, Barański A (2011) Slov Chim Acta $58: 41$

4. Jasiński R, Michorczyk P, Jasińska E, Koifman O, Barański A (2011) Izv Vuzov Khimya Khim Tekhnol 54:89

5. Jasiński R, Barański A (2010) J Mol Struct (TheoChem) 949:8

6. Jasiński R, Rzyman M, Barański A (2010) Collect Czech Chem Commun 75:919

7. Kwiatkowska M, Jasiński R, Mikulska M, Barański A (2010) Monatsh Chem 141:545

8. Jasiński R, Wąsik K, Mikulska M, Barański A (2009) J Phys Org Chem 22:717

9. Jasiński R, Kwiatkowska M, Barański A (2009) J Mol Struct (TheoChem) 910:80
10. Jasiński R, Kwiatkowska M, Barański A (2007) Wiad Chem 67:485

11. Firestone R (1999) Tetrahedron 52:14459

12. Sauer JJ, Sustmann R (1980) Angew Chem Int Ed 19:779

13. Itoh K, Kioth K, Kishimoto S (2006) Can J Chem 84:392

14. Ernd M, Heuschmann M, Zipse H (2005) Helv Chim Acta 88:1491

15. Lakhdar S, Terrier F, Vichard D, Berionni G, El-Guesmi N, Goumont R, Boubaker T (2010) Chem Eur J 16:5681

16. Schwietlick K (1971) Kinetische Metoden zur Untersuchung von Reaktionsmechanismen. VEB Deutscher Verlag der Wissenschaften, Berlin

17. Anslyn EV, Dougherty DA (2006) Modern physical organic chemistry. University Science Books, Sausalito

18. Reichardt C, Welton T (2011) Solvents and solvent effects in organic chemistry. Wiley-VCH, Weinheim

19. Kartitzky AR, Fara DC, Yang H, Tämm K, Tämm T, Karelson M (2003) Chem Rev 103:175

20. YuYa Fialkov (1990) Rastovitel kak sredtsvo upravlenya khimiheskim processom. Khimya, Leningrad

21. Domingo LR, Saez JA (2009) Org Biomol Chem 7:3576

22. Wassermann A (1965) Diels-Alder reactions. Organic background and physico-chemical aspects. Elsevier, Amsterdam

23. Onishchenko AS (1964) Diene synthesis. Israel Program for Scientific Translations, New York

24. Fringuelli F, Taticchi A (1990) Dienes in the Diels-Alder reaction. Wiley, New York

25. Sustmann R, Tappanchai S, Bandmann H (1996) J Am Chem Soc 118:12555

26. Buckingham AD (1978) In: Pullman B (ed) Intermolecular interactions: from diatomics to biopolymers. Wiley, New York

27. Kaplan IG (1982) Introduction to intermolecular interactions. Izd Nauka, Moscow

28. Leniewski A (1993) In: Wróbel A (ed) Preparatyka i elementy syntezy organicznej. PWN, Warszawa

29. Arnold RT, Scott GP (1963) In: Noland WE (ed) Organic syntheses, Collective volume IV. Wiley, New York, p 238

30. Ried W, Köhler E (1956) Liebigs Ann Chem 598:144 